\title{
A NECESSIDADE DE UMA GESTÃO PÚBLICA EFICAZ PARA AMENIZAR OS EFEITOS DA SECA NA REGIÃO NORDESTE
}

Mélittem Brito Azevedo - melittem@hotmail.com Instituto Federal de Educação, Ciência e Tecnologia da Bahia. Manoel Messias Coutinho Meira - yoshishairy@hotmail.com Instituto Federal de Educação, Ciência e Tecnologia da Bahia. 


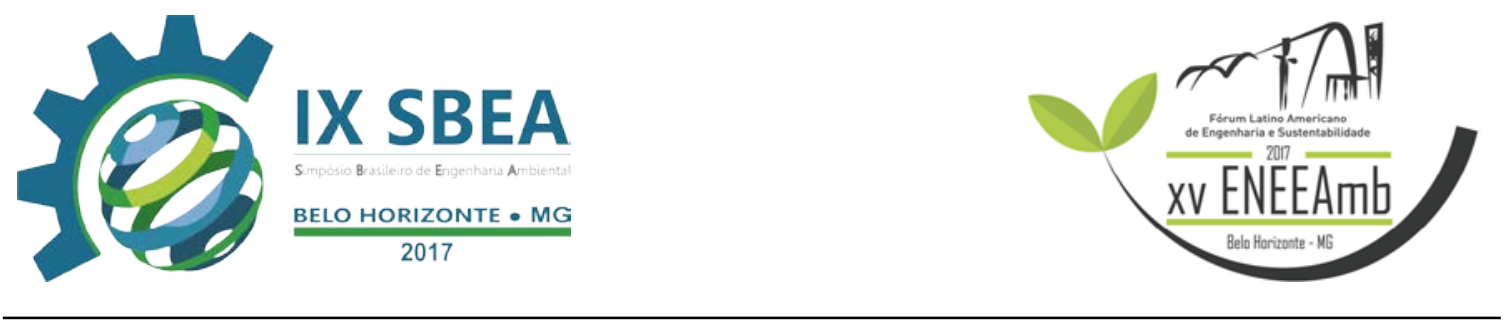

\section{RESUMO}

O seguinte trabalho propõe uma análise sobre a quantidade de reconhecimentos de situações de emergência verificadas na região nordeste do Brasil no decorrer de dez anos, e enfatiza a relevância de políticas públicas adequadas para atender as áreas afetadas. A pesquisa foi realizada de forma documental, pois fez uso de dados estatísticos. Conforme os resultados obtidos, há a percepção de quais localidades são mais impactadas, observa-se o contraste expressivo entre as demais regiões brasileiras e a região nordeste. As informações referentes aos primeiros quatro meses do ano de 2017 retratam as principais causas das situações de emergência, estas foram resultantes da estiagem que acomete grande parte dos municípios nordestinos. As secas prolongadas são resultado das características do clima semiárido predominante na região. Ao se constatar a seca como causa fundamental dos relatos de emergência, presume-se a necessidade de políticas públicas que administrem os recursos de forma a atender satisfatoriamente as demandas da região e amenizar os impactos socioeconômicos e ambientais gerados.

Palavras-chave: Estiagem, Gestão pública, Nordeste, Reconhecimentos de emergência.

\section{OBJETIVO}

Este trabalho possui como principal objetivo, relatar o contraste entre a quantidade de reconhecimentos de situações de emergência da região nordeste e evidenciar os estados mais afetados. Assim como ressaltar a importância de uma gestão pública adequada para a administração de recursos para amenizar os impactos provocados pela seca.

\section{METODOLOGIA}

Os dados coletados são oriundos da plataforma online do Ministério Nacional da Integração na área de proteção e defesa civil. As informações foram selecionadas para um período de dez anos - 2007 a 2016 - e a partir destas foi feita uma análise sobre a região e os estados mais afetados pelos reconhecimentos de emergência, assim como analise das causas nos primeiros quatro meses do ano de 2017. 


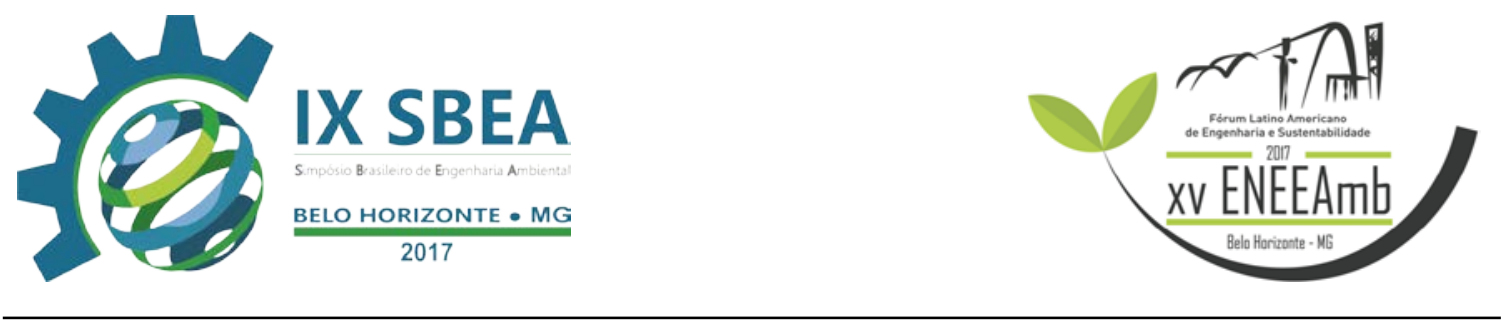

Trata-se de uma pesquisa documental primária, pois houve a consulta a documentos de arquivos públicos, e estes estavam veiculados no meio digital. De acordo com Lakatos e Marconi (2003), os dados obtidos com as estatísticas, com maior cobertura no espaço e tempo, permitem o alcance de resultados mais expressivos. Além disso, consideram a existência de três principais vertentes para o uso informações estatísticas. Os dados deste estudo utilizaram a vertente que busca averiguar uma teoria social. A teoria de que o Nordeste é demasiadamente afetado pela seca, importante inferir que os estados que compõe esta região não são afetados de forma semelhante.

\section{RESULTADOS E DISCUSSÃO}

De acordo com a Instrução Normativa n. 1 de 24 de agosto de 2012, desastre é conceituado como: uma grave perturbação, de origem natural ou antropogênica, ao desenvolvimento regular de uma comunidade, responsável por causar inúmeros prejuízos nos âmbitos socioeconômicos e ambientais. Nestes casos, quando os danos provocados por este tipo de evento requerem uma maior assistência dos órgãos públicos, a área afetada deve declarar situação de emergência.

Para o reconhecimento do estado crítico de emergência, o desenvolvimento social necessita ter sido comprometido de tal forma que o estado ou município não tenha plena capacidade para solucionar a situação, cabendo ao governo federal prestar o devido auxílio à área afetada. Estas condições são normalmente causadas por chuvas intensas ou secas prolongadas.

A correlação entre as secas prolongadas e a região Nordeste é uma característica climática natural associada ao clima semiárido - caracterizado pelo baixo índice pluviométrico e baixa umidade relativa do ar, como constata Ribeiro (1999). Esta associação da região com a seca está intimamente relacionada com os principais aspectos do clima, os quais, segundo Araújo (2011) podem ser sintetizados em: predominância de altas temperaturas, precipitações escassas e concentradas em um curto intervalo de tempo e o déficit hídrico para a vegetação. O clima semiárido possui 969.589,4 km², e não abrange completamente e exclusivamente a região nordestina, visto que inclui parte do estado de Minas Gerais e não inclui o estado do Maranhão. 


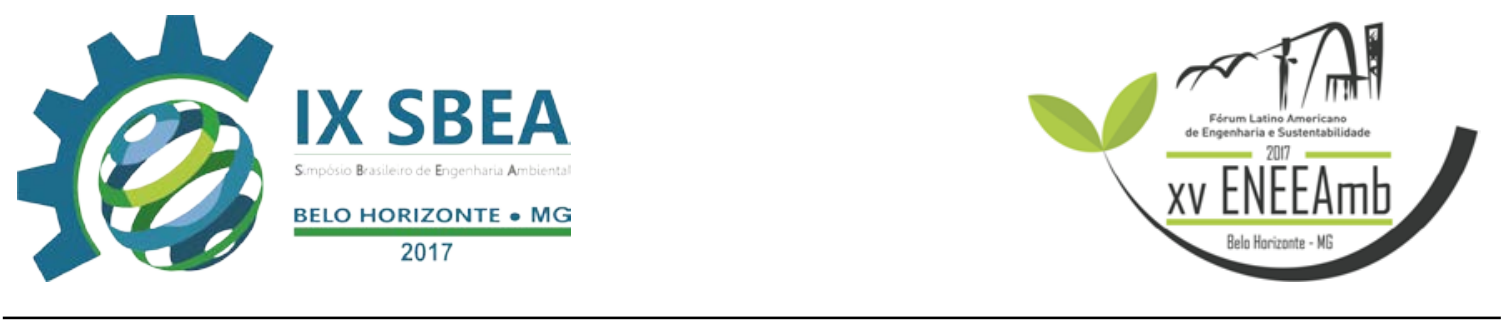

A precipitação varia entre $250 \mathrm{~mm}$ ano e $1.000 \mathrm{~mm}$ ano concentrados em dois ou três meses, porém o índice de evaporação equivale a cerca de $2.000 \mathrm{~mm}$ ano-1 (MAGALHÃES, 2012). Em decorrência disso, os longos períodos de estiagem são recorrentes. Como consequência há os desequilíbrios socioeconômicos, que afetam diretamente o bem-estar local; os hidrológicos, associados ao decréscimo no nível dos reservatórios; os agropecuários, como perda de cultivos e animais e os impactos à natureza, relacionados à degradação do solo e desertificações.

Estes impactos no ambiente demonstram a severidade da seca, o que implica na necessidade de políticas públicas adequadas. Trata-se de um desastre natural de ampla ocorrência no mundo e no que se refere ao semiárido brasileiro, falta infraestrutura para a convivência com esta adversidade (SÍLVIA et al, 2013). No entanto, como ressalta Campos (2014), os programas sociais implantados pelos governos no decorrer do tempo reduziram os impactos sobre as populações. Nota-se que é imprescindível a continuidade e melhoria de ações que garantam o convívio da população com o meio ambiente.

A região Nordeste concentra a maior parcela de registros de situações de emergência quando comparada ao somatório das outras regiões brasileiras, com base nos dados pesquisados para o período de dez anos. A Figura 1 ilustra este comparativo.

Figura 1 - Reconhecimento de estado de emergência do Nordeste em relação à outras regiões.

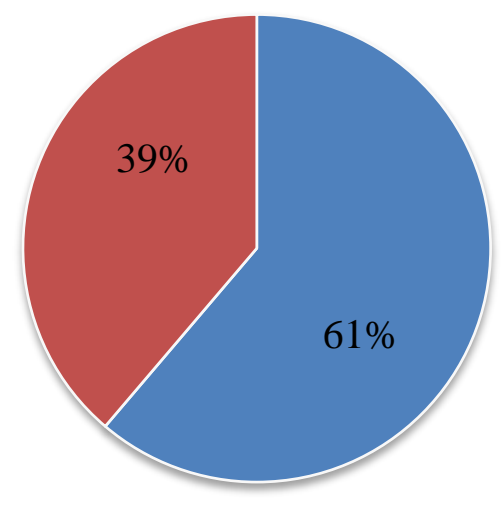

- Nordeste

- As outras regiões 


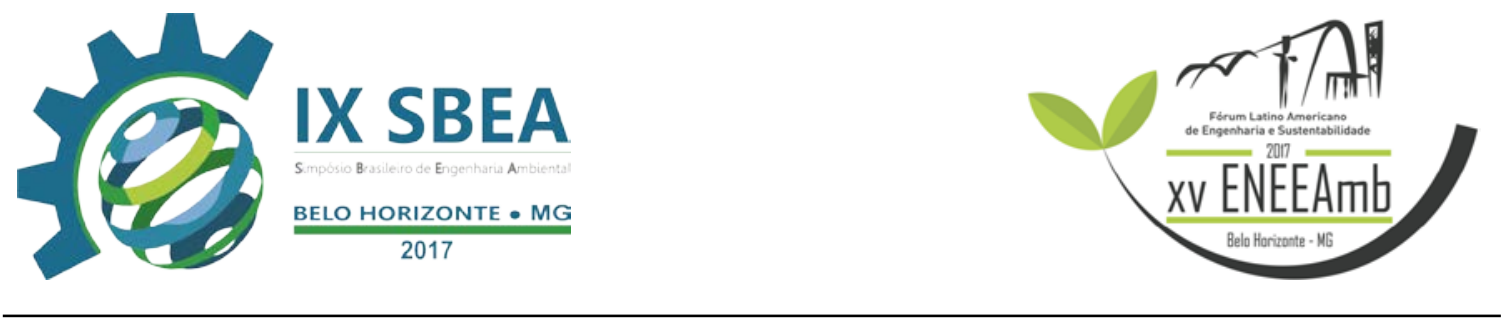

Evidencia-se a importância de uma gestão pública adequada que amenize os impactos causados palas variações climáticas, os quais interferem de forma expressiva no bem-estar populacional.

Ao se analisar os estados que compõe a região nordeste, identifica-se as seguintes porcentagens, conforme a Figura 2:

Figura 2 - Registros por estado em uma década.

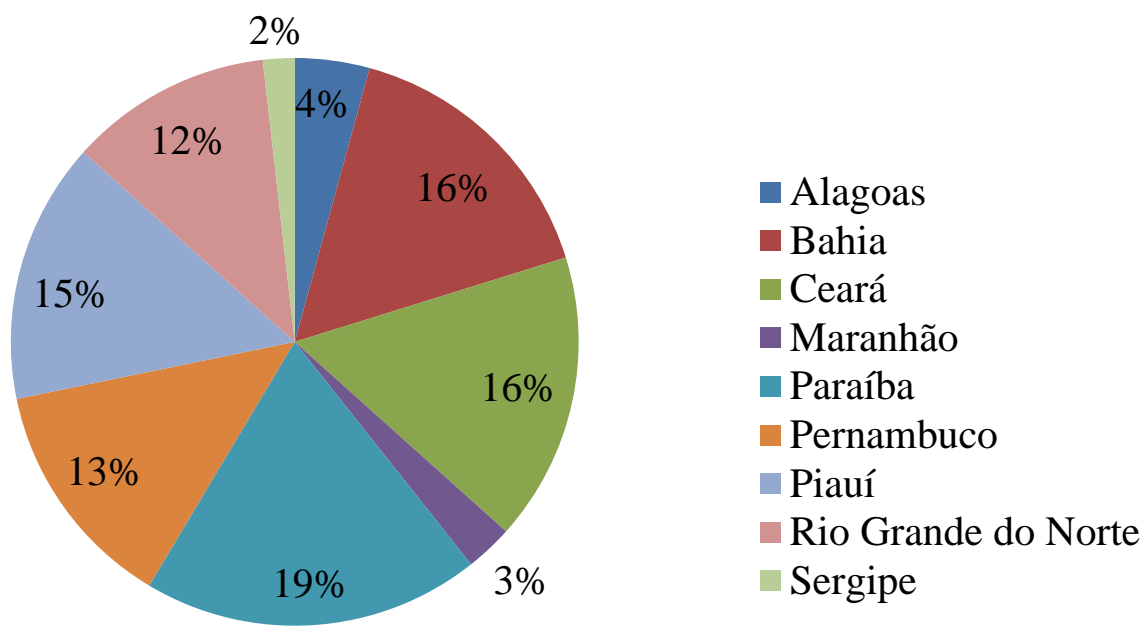

Os estados que apresentam os menores índices são Sergipe, Maranhão e Alagoas. Paraíba concentra o maior número de casos, seguida por Ceará e Bahia. Logo, estes estados com as maiores ocorrências necessitam de uma maior assistência do governo.

Com base na pesquisa realizada em relação a quantidade de reconhecimentos de emergência na região nordeste entre os anos de 2007 e 2016, foram obtidos os seguintes dados:

Tabela 1 - Reconhecimentos de emergência em dez anos.

\begin{tabular}{|c|c|}
\hline Ano & $\begin{array}{c}\text { Quantidade de } \\
\text { reconhecimentos } \\
\text { de emergência }\end{array}$ \\
\hline
\end{tabular}




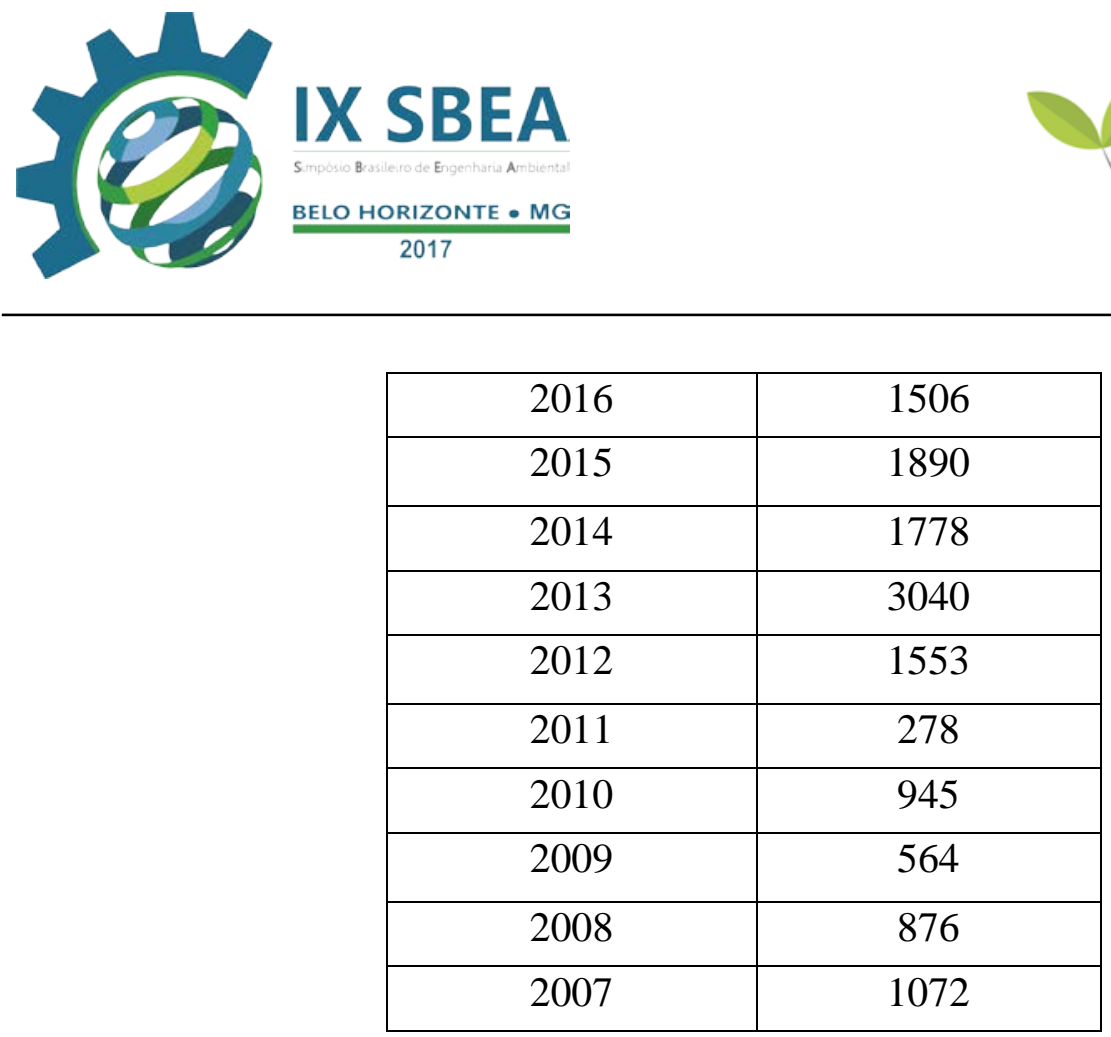

Percebe-se que não se trata de uma variação sistemática, uma vez que são números oriundos das consequências climáticas. No entanto, a partir de 2012 há um aumento significativo em relação aos cinco anos anteriores, pois antes os registros se concentravam na faixa de 200 a 1110 e, a partir deste ano, não há valores inferiores a 1500, revelando um acréscimo das situações dependentes do auxílio federal.

Ao relacionar os reconhecimentos de emergência com as causas relatadas nos primeiros meses do ano de 2017, do mês de janeiro ao dia cinco de maio, a estiagem pode ser considerada a principal responsável:

Tabela 2 - Situações de emergência - atualizadas em 05 de maio de 2017.

\begin{tabular}{|c|c|c|c|}
\hline Localidade & Seca/Estiagem & Chuvas & Outros \\
& & & \\
\hline Alagoas & 74 & - & 01 \\
\hline Bahia & 277 & 05 & - \\
\hline Ceará & 94 & - & - \\
\hline Maranhão & - & 02 & - \\
\hline Paraíba & 197 & - & - \\
\hline Pernambuco & 71 & - & - \\
\hline Piauí & 43 & - & - \\
\hline Rio Grande do Norte & 153 & - & - \\
\hline Sergipe & 28 & - & - \\
\hline Total & 887 & 07 & 01 \\
\hline
\end{tabular}




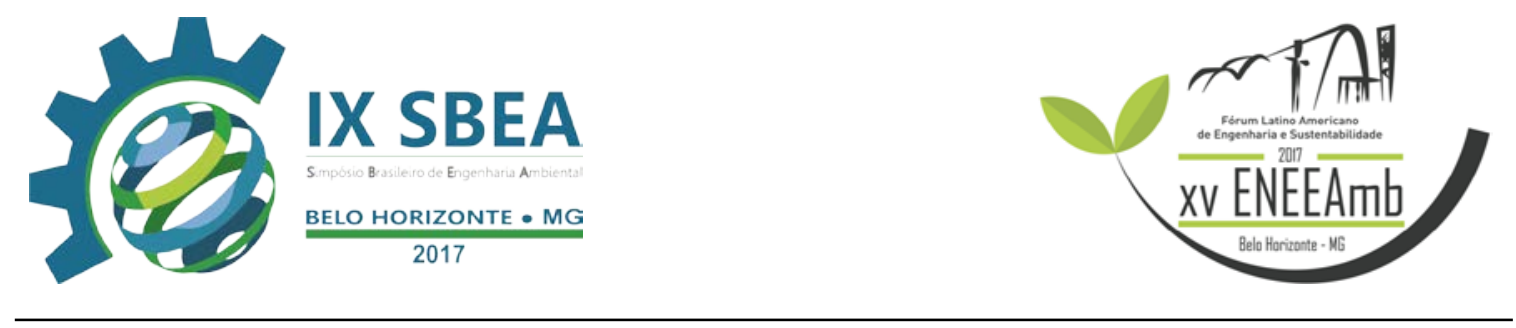

\begin{tabular}{|l|l|l|l|}
\hline Brasil & 952 & 163 & 73 \\
\hline
\end{tabular}

Fonte: Ministério da Integração Nacional, 2017. Adaptado.

Em relação à tabela exemplificada, no que se refere às chuvas, são consideradas as situações de: deslizamentos, inundações, enxurradas, alagamentos, ciclones, tornado, granizo, vendaval e chuvas intensas. Quanto ao termo outros, são identificados os casos de: doenças infecciosas virais, erosão de margem fluvial, erosão continental (voçorocas), erosão costeiro-marinha e colapso de edificações.

Percebe-se que a quantidade de casos provenientes de chuvas ou outros incidentes são pouco representativos, pois a estiagem é o fator preponderante. Verificase também que o contraste entre o Nordeste e as demais regiões continua expressivo, assim como os estados com os maiores índices registrados nos últimos dez anos continuam a se manter dessa forma, não houve alteração quanto a esses aspectos.

\section{CONCLUSÕES/RECOMENDAÇÕES}

Em virtude do que foi exposto, percebe-se que o Nordeste é a região mais carente de auxílio federal quanto aos reconhecimentos de emergência referentes a seca. É importante enfatizar o fato de que os estados não são atingidos da mesma forma, pois este fenômeno natural é predominante nas áreas com ocorrência do clima semiárido.

As medidas paliativas para o combate à seca têm se demonstrado ineficazes para sua redução ou minimização efetiva, visto que pouco mudou nesse cenário em dez anos. Nesse sentido, faz-se necessário investir em programas de auxílio a longo prazo concomitante à disposição emergencial, visto que, nesse sentido, prevê-se uma redução do gasto efetivo com a recuperação de danos.

O estado da Paraíba, Ceará e Bahia, que concentras o maior número de casos de declaração de situação de calamidade devem ser o foco dos investimentos a nível nacional. Nesse contexto, o número de reconhecimentos de emergência é um número crescente, no entanto, é uma tendência contrária à esperada, visto que o auxílio a essas áreas tende a acontecer.

Desse modo, torna-se essencial a administração adequada dos recursos destinados para a região semiárida a fim de amenizar os inúmeros impactos provocados 


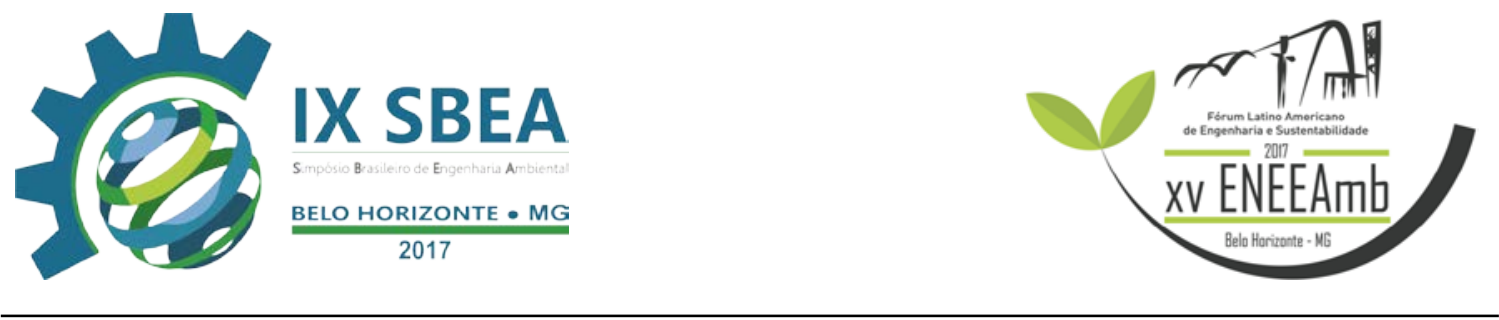

pelos longos períodos de estiagem e possibilitar uma convivência harmoniosa entre a população e o meio ambiente.

\section{REFERÊNCIAS BIBLIOGRÁFICAS}

ARAÚJO, Sérgio Murilo Santos de. A região semiárida do nordeste do Brasil: Questões Ambientais e Possibilidades de uso Sustentável dos Recursos. Rios Eletrônica, v. 5, n. 5, p. 90-98, 2011. Disponível em: $<$ http://www.fasete.edu.br/revistarios/media/revistas/2011/a_regiao_semiarida_do_nord este_do_brasil.pdf >. Acesso em: 30 de maio de 2017.

Brasil. Instrução Normativa n. 1 de 24 de agosto de 2012. Estabelece procedimentos e critérios para a decretação de situação de emergência ou estado de calamidade pública pelos Municípios, Estados e pelo Distrito Federal. Diário Oficial da União, 30 de agosto de 2012. Seção 1, p. 30-39. Disponível em: <http://www.defesacivil.sp.gov.br/v2010/portal_defesacivil/conteudo/documentos/Instr ucaoNormativa24082012.pdf> . Acesso em: 30 de maio de 2017.

CAMPOS, José Nilson B. Secas e políticas públicas no semiárido: ideias, pensadores e períodos. Estudos Avançados, São Paulo, v. 28, n. 82, 2014. Disponível em: <http://www.scielo.br/scielo.php?script=sci_arttext\&pid=S01030142014000300005 $>$. Acesso em: 31 de maio de 2017.

LAKATOS, Eva Maria; MARCONI, Maria de Andrade. Fundamentos da metodologia científica. 5. ed. São Paulo: Atlas, 2003.

MAGALHÃES, T. Caatinga, ecossistema heterogêneo. IHU On-Line - Revista do Instituto Humanitas Unisinos, São Leopoldo, n. 389, p. 11-13, abr. 2012.

Ministério da Integração Nacional. Nova delimitação do semiárido brasileiro. Brasília: MIN/Secretaria de Políticas de Desenvolvimento Regional, 2005. Disponível em:<http://www.mi.gov.br/c/document_library/get_file?uuid=0aa2b9b5-aa4d-4b55a6e1-82faf0762763\&groupId=24915> . Acesso em: 20 de maio de 2017.

Reconhecimentos vigentes. Disponível em: <http://www.mi.gov.br/reconhecimentos-realizados>. Acesso em: 8 de maio de 2017.

RIBEIRO, Rafael Winter. Seca e Determinismo: a Gênese do Discurso do Semiárido Nordestino. Anuário do Instituto de Geociências - UFRJ, v. 22, 1999. Disponível em: <http://www.anuario.igeo.ufrj.br/anuario_1999/vol22_60_91.pdf>. Acesso em: 27 de maio de 2017. 
SILVA, Virgínia Mirtes de Alcântara; PATRÍCIO, Maria da Conceição Marcelino; RIBEIRO, Victor Herbert; MEDEIROS, Raimundo Mainar. O desastre seca no nordeste brasileiro. Questões Contemporâneas, v. 12, n.2, 2013. Disponível em: $<$ http://www.e-publicacoes.uerj.br/index.php/polemica/article/view/6431/4857>. Acesso em: 30 de maio de 2017. 